\title{
Design de hipermídia: a sistematização de processos no desenvolvimento de materiais didáticos digitais para Educação a Distância
}

\author{
Hypermedia design: systematization of processes in the development of digital \\ didactic materials for Distance Education
}

\author{
Jaqueline de Ávila, Giselle Schmidt Alves Díaz Merino, Eugenio Andrés Díaz Merino
}

design, hipermídia, processos, material didático digital

O presente artigo tem como objetivo desenvolver um guia, em formato de hipermídia, a fim de sistematizar práticas e processos de uma equipe de design gráfico (DG) que atua no desenvolvimento de materiais didáticos digitais para cursos na modalidade a distância. Para isso, considera-se que a qualidade didática e técnica dos materiais está associada à organização dos fluxos de trabalho e dos processos comunicacionais entre aqueles que os produzem - geralmente, equipes interdisciplinares. Assim, utilizando estratégias de design, os processos de desenvolvimento da equipe de DG podem ser planejados, documentados, executados e repensados (quando necessário), gerando um ciclo proposto a partir de vivências, experiências e diretrizes já existentes (pesquisa bibliográfica), o qual muitas vezes ocorre de forma não documentada. Após implementação e validação do protótipo com a equipe, constatou-se que a mesma sente-se mais segura tendo um material manuseável e acessível sobre suas práticas e que o material proposto contribui para melhorias nos processos organizacionais e cotidianos da equipe, demonstrando a importância do design da informação no contexto apresentado.

design, hypermedia, processes, digital didactic material

This article aims to develop a guide, in a hypermedia format, in order to systematize the practices and processes of a graphic design team (DG) that acts in the development of digital didactic materials for courses in the distance modality. For this, it is considered that the didactic and technical quality of the materials is associated to the organization of the workflows and the communication processes between those who produce them - generally, interdisciplinary teams. Thus, by using design strategies, the development processes of the DG team can be planned, documented, executed and rethought (when necessary), generating a cycle proposed from existing experiences, experiences and guidelines (bibliographic research), which often occurs in an undocumented way. After the implementation and validation of the prototype with the team, it was found that it feels safer having a material that is manageable and accessible about its practices and that the proposed material contributes to improvements in the organizational and daily processes of the team, demonstrating the importance of information design in the context presented.

\section{Introdução}

Com a disseminação das Tecnologias Digitais de Informação e Comunicação (TDIC), a quantidade de materiais disponíveis para consulta, na web, é imensa. Verifica-se que, em 2011, havia em torno de um trilhão de páginas na web, dado que, atualmente, já deve estar bastante ultrapassado, e torna-se inviável a tentativa de contabilizá-lo. De qualquer forma, as facilidades que estas tecnologias trouxeram para o dia-a-dia da sociedade são inegáveis, e "vêm modificando fortemente as possibilidades de interação a distância" (BELLONI, 1999: 58), pois é por meio delas que os aprendentes ${ }^{1}$ têm acesso a diferentes recursos digitais, disponibilizados através de interfaces, materiais didáticos, vídeos, hipermídias, entre outros.

Neste sentido, fica evidente a importância desses recursos para a Educação a distância (EaD), assim como o cuidado necessário para desenvolvê-los. A forma de organização das

\footnotetext{
${ }^{1}$ Considera-se aprendente o "indivíduo autônomo, capaz de gerir seu próprio processo de aprendizagem" (BELLONI, 1999: 6).

Anais do 8 CIDI e 8 CONGIC

Guilherme Santa Rosa; Cristina Portugal (orgs.)

Sociedade Brasileira de Design da Informação - SBDI

Natal | Brasil | 2017

ISBN 978-85-212-1305-5
} 
equipes responsáveis pelo desenvolvimento dos mencionados recursos, no contexto desta pesquisa, preza por uma série de diretrizes, desde o perfil (tanto multidisciplinar quando específico) de profissionais e bolsistas, até o fluxo de trabalho proposto. Como resultado, equipes com integrantes de diferentes áreas trabalham coletivamente, e geram fluxos (de processos e de documentos) bastante extensos.

Se considerarmos que a interface é o campo de comunicação entre o homem e a máquina, conforme pontua Royo (2008: 89), podemos inferir que ela precisa seguir determinadas diretrizes para alcançar seus objetivos. Portanto, para que as interfaces sejam eficientes, a dimensão tecnológica (voltada para o design) deve estar coerente com a dimensão didáticopedagógica. Desta forma, a preocupação iminente desta pesquisa é aproximar ambas as frentes com a ajuda de estratégias da gestão de design (GD). Por meio de um guia, em formato digital, têm-se como objetivo sistematizar boas práticas em relação ao desenvolvimento de materiais didáticos digitais (dimensão operacional da GD), visando ao planejamento, organização e à permanente melhoria de processos internos da equipe envolvida (dimensão estratégica da GD).

Sendo assim, a pesquisa se estrutura trazendo, primeiramente, a explicitação dos procedimentos metodológicos, seguido da fundamentação teórica, que relaciona design digital, gestão de design, produção de materiais didáticos digitais e design da informação. $\mathrm{Na}$ sequência, há o detalhamento do desenvolvimento do guia, a etapa de validação do protótipo e os resultados obtidos, que também são discutidos nas considerações finais deste trabalho.

\section{Procedimentos metodológicos e cenário de pesquisa}

A presente pesquisa foi realizada em duas (02) fases, uma teórica e uma prática, conforme demonstra a Figura 1, abaixo.

Figura 1: Procedimentos metodológicos

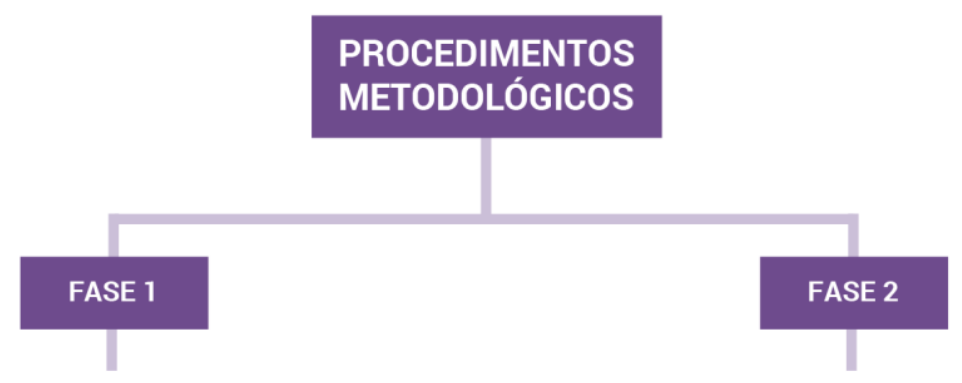

0 que foi feito: Fundamentação teórica Como foi feito: Pesquisa bibliográfica Conteúdo: Design digital; Gestão de Design; Produção de materiais didáticos digitais para EAD); Design da Informação.
0 que foi feito: Desenvolvimento do produto Como foi feito: Metodologia projetual - GODP Conteúdo: Oportunidades; Prospecção; Lev. de dados; Análise de dados; Criação; Execução; Testes e Resultados.

Fonte: Elaborada pelos autores (2017)

Foi utilizado como metodologia projetual o Guia de Orientação para o Desenvolvimento de Projetos - GODP, configurada por oito etapas que se baseiam na

[...] coleta de informações pertinentes ao desenvolvimento da proposta, ao desenvolvimento criativo, a execução projetual, a viabilização e verificação final do produto (MERINO, 2014: 92).

Quanto ao ambiente de estudo, trata-se de um laboratório de desenvolvimento de materiais educacionais digitais para formações na modalidade a distância, da Secretaria de Educação a Distância da Universidade Federal de Santa Catarina (SEAD-UFSC). Nesse contexto, é comum a existência de equipes interdisciplinares, com especialistas de diversas áreas do conhecimento trabalhando conjuntamente. Além disso, o laboratório trabalha majoritariamente com bolsistas, ou seja, estudantes de graduação e pós-graduação, o que resulta em trocas 
constantes dos integrantes das equipes, posto que, ao se formarem perdem o vínculo com a universidade e necessitam encerrar os trabalhos no projeto.

A SEAD tem como objetivo a execução de projetos que utilizem, de modo inovador, as TDIC (UFSC, 2017). O projeto analisado faz parte de uma parceria governamental existente entre a IFES e o Ministério da Justiça e Segurança Pública. Em se tratando de material para o Governo Federal, os prazos são estipulados com o parceiro, nesse caso diretamente com a Secretaria Nacional de Políticas sobre Drogas, e geralmente são exíguos, haja vista que os fluxos de trabalho são extensos e intensos, porque os materiais precisam passar por várias instâncias de aprovação, antes de estarem disponíveis ao público.

Tendo como foco principal os processos internos de uma equipe de design gráfico (DG), pretende-se, neste trabalho, demonstrar de que forma as práticas da equipe podem ser planejadas, documentadas, executadas e repensadas (quando necessário), utilizando estratégias de gestão de design. Verifica-se certa falta de documentação que, por vezes, gera problemas de comunicação e também de retrabalho. Por isso, foi desenvolvido um material em formato de hipermídia, chamado "Guia de Boas Práticas", validado com a própria equipe (por meio de questionário), que serve de consulta, objetivando que a equipe de DG tenha mais facilidade de acesso à informação ao desenvolver seu trabalho.

\section{Fundamentação teórica}

\subsection{Design digital}

Para que o designer de interface possa efetivamente trabalhar na criação de produtos, ele utiliza ferramentas físicas e conceituais específicas. Nesse sentido, o design e as tecnologias trabalham de forma conjunta. Royo (2008: 13) afirma que o design depende da tecnologia "para poder desenvolver sua linguagem e, com isso, ter espaços de comunicação para atuar". Assim, cada vez que surge um novo meio, aparece um novo espaço de ação e a "disciplina do design reformula suas ferramentas físicas e conceituais" (ROYO, 2008: 13).

Com esses constantes avanços, especialmente em relação à criação do ciberespaço, abrese mais possibilidades de interação e, assim, nasce e cresce exponencialmente o design digital. A importância do design da informação, no contexto do presente artigo, se dá a partir do momento em que o material será utilizado no cotidiano de uma equipe, necessitando, portanto, ser claro, objetivo e coerente, possibilitando interação com o sistema.

Observa-se tal cotidiano a partir da visão da gestão de design, considerada como o "conjunto de atividades de diagnóstico, coordenação, negociação e Design" (MARTINS; MERINO, 2008: 151). Sendo assim, para esta pesquisa a gestão de design é mais focada na qualidade dos processos, tornando-se uma "porta de entrada para o design nas organizações" (MOZOTA, 2011).

\subsection{Gestão de design}

De acordo com Mozota (2011: 227), existem três níveis de abordagem em gestão de design, em relação à tomada de decisão: a) nível operacional - o primeiro passo para a integração do design na instituição; b) nível funcional - passa-se a existir uma função de design na empresa; c) nível estratégico - o design atuando para "unificar e transformar a visão da empresa" (MOZOTA, 2011: 227).

No caso do da instituição em questão, e da equipe de DG presente no projeto focalizado nesta pesquisa, consegue-se ver claramente os níveis operacional e funcional. Sendo assim, o foco desta pesquisa é aprofundar-se mais no nível estratégico, considerando quatro papéis essenciais (especificados abaixo), sendo o quarto o mais importante neste contexto.

Visualizar a estratégia empresarial

Procurar a competência central 
Reunir informações de mercado

Inovar em processos de gerenciamento (SEIDEL, 2000; MOZOTA, 2011).

De acordo com a Figura 2 abaixo, elaborada com base em Martins e Merino (2008), podese entender melhor as nuances de cada nível da gestão de design atuando enquanto ações estratégicas nas organizações.

Figura 2: Níveis da gestão de design

\begin{tabular}{|c|c|c|c|}
\hline $\begin{array}{l}\text { INFLUÊNCIA } \\
\text { DO DESIGN }\end{array}$ & $\begin{array}{l}\text { NÍVEIS DE } \\
\text { DECISÕES }\end{array}$ & $\begin{array}{l}\text { NÍVEIS DE CRIAÇÃO } \\
\text { DE VALOR }\end{array}$ & $\begin{array}{l}\text { NÍVEL DE } \\
\text { COMPETÊNCIAS }\end{array}$ \\
\hline $\begin{array}{l}\text { Sobre a oferta: dá um sentido ao } \\
\text { discurso e ao objeto. }\end{array}$ & Gestão de Design operacional. & $\begin{array}{l}\text { Atuação sobre a oferta da orga- } \\
\text { nização ou função diferenciadora } \\
\text { do Design. }\end{array}$ & $\begin{array}{l}\text { Design ação ou como competên- } \\
\text { cia econômica. Criação de valor } \\
\text { sobre as funções da organização. }\end{array}$ \\
\hline $\begin{array}{l}\text { Sobre os homens: ajuda a mobili- } \\
\text { zar e motivar pela facilidade de } \\
\text { circulação de informações, aproxi- } \\
\text { mando diferentes atores num } \\
\text { mesmo projeto. }\end{array}$ & Gestão de Design tático. & $\begin{array}{l}\text { Atuação sobre a empresa ou } \\
\text { função coordenadora do Design. }\end{array}$ & $\begin{array}{l}\text { Design função ou como compe- } \\
\text { tência controladora. Criação do } \\
\text { valor sobre as funções suporte, } \\
\text { em particular sobre a gestão da } \\
\text { inovação e da tecnologia. }\end{array}$ \\
\hline $\begin{array}{l}\text { Sobre a empresa: facilita a formu- } \\
\text { lação de um projeto que incite a } \\
\text { visão do núcleo estratégico. }\end{array}$ & Gestão de Design estratégico. & $\begin{array}{l}\text { Atuação do Design sobre o ambi- } \\
\text { ente empresarial ou função trans- } \\
\text { formadora do Design. }\end{array}$ & $\begin{array}{l}\text { Design visão ou como competên- } \\
\text { cia psicológica, influência na com- } \\
\text { preensão do ambiente e transfor- } \\
\text { mação de procedimentos. }\end{array}$ \\
\hline
\end{tabular}

Fonte: Elaborada pelos autores (2016), com base em Martins e Merino (2008: 200).

Ao basear-se na gestão de design a partir de seus 3 níveis, a intenção desejada é de que haja um enriquecimento dos processos e indivíduos, sistematizando práticas do dia-a-dia e fomentando a constante avaliação das mesmas. No sentido estratégico do design, Mozota (2011) pontua exatamente a questão do "repensar processos" quando contempla acerca da gestão do design e suas aplicações.

\subsection{Produção de materiais didáticos digitais para Educação a distância: o design da informação}

De acordo com Belloni (1999) e Renneberg (2010), já sabemos que a modalidade de EaD requer um olhar individualizado para cada aprendente, de acordo com diferentes perfis cognitivos. Por isso, coloca-se bastante importância no processo de desenvolvimento de materiais didáticos para esta modalidade, visto que os materiais são o principal elo entre o sujeito e a aprendizagem.

Entende-se que as tecnologias, por si só, não garantem nenhum tipo de mudança metodológica na $\mathrm{EaD}$, mas com certeza mostram novas possibilidades e novas oportunidades no ciberespaço. Tais oportunidades só se fazem possíveis se o material desenvolvido conseguir, de fato, contribuir com o processo de aprendizagem dos sujeitos. Considera-se que se as equipes envolvidas no processo de desenvolvimento "se apropriarem, dominarem e compreenderem as tecnologias de modo crítico e criativo", conforme pontua Alava (2002), os materiais desenvolvidos podem ser mais eficazes pedagogicamente. Entende-se, então, que a importância do design no contexto do desenvolvimento de materiais didáticos digitais para a Educação a Distância precisa ser considerada enquanto ferramenta e enquanto estratégia.

Neste sentido, o design da informação atua no processo de trabalho da equipe fortemente, visto que seu objetivo é "organizar e apresentar dados, transformando-os em informação válida e significativa" (PORTUGAL, 2013: 48).

Além disso, a constituição de equipe e seu processo formativo é muito importante no contexto de desenvolvimento de materiais didáticos para a EaD. Percebe-se, na prática, que imbuir os indivíduos, fazendo-os sentirem-se parte do todo, inclusive da tomada de decisões, contribui para materiais didáticos mais coerentes. Porém, a tarefa de fazer as equipes entenderem a importância dos aspectos pedagógicos e como eles refletem na qualidade do 


\section{CIDI 2017

material é complexa, visto que, em alguns contextos, este aspecto não é tarefa própria do design.

Utiliza-se, então, a abordagem do design em situações de ensino-aprendizagem, proposta por Portugal (2013), que sugere que o design "esteja mais consciente para oferecer soluções efetivas no que se refere aos ambientes educacionais hipermídia" (PORTUGAL, 2013: 32). Partindo desta abordagem, o produto desta pesquisa visa enriquecer o processo de produção de materiais didáticos digitais e, consequentemente, gerar materiais com maior qualidade didática e gráfica.

\section{Desenvolvimento do guia de boas práticas: etapas metodológicas}

Para o desenvolvimento do guia de boas práticas foi utilizada a metodologia intitulada "Guia de Orientações para o Desenvolvimento de Produtos" - GODP (Figura 3), proposta por Merino (2014). De acordo com a autora:

O GODP foi formulado a partir de literaturas de Design e outras áreas correlatas, por meio da contribuição de vários autores. Com base numa compilação de diversas metodologias, que foram reestruturadas e adaptadas, para que se pudesse dar forma a um guia de orientação que venha contemplar os aspectos intervenientes no desenvolvimento de projetos (MERINO, 2014: 90).

Figura 3: Apresentação da metodologia e momentos de projeto

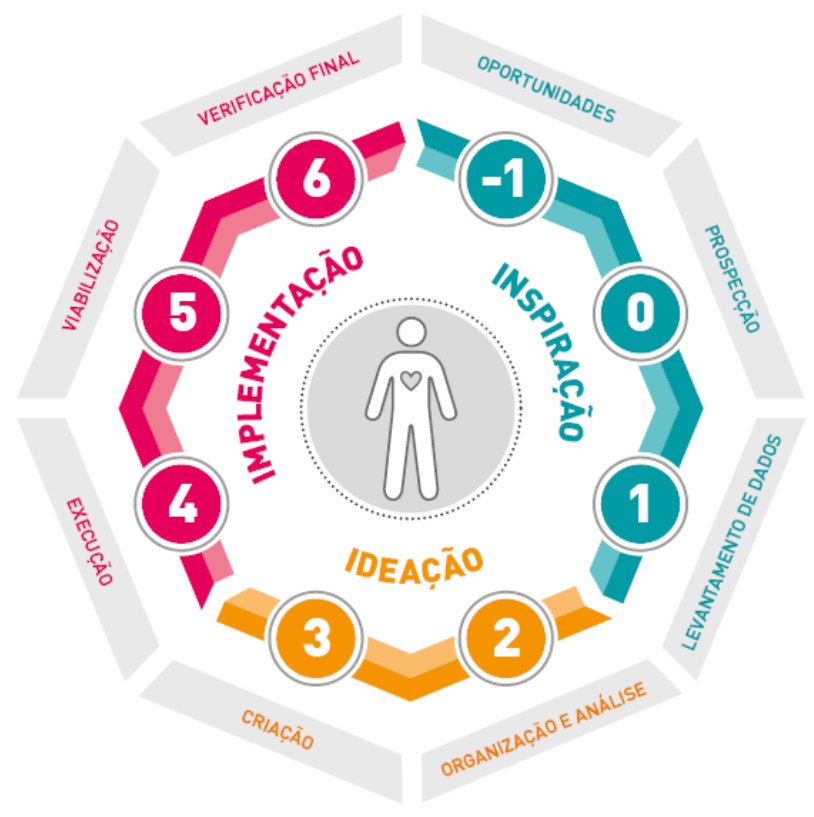

Fonte: Merino (2016).

Sendo assim, no GODP são apresentados três momentos no processo de desenvolvimento de um produto ou projeto: Inspiração, contemplando as etapas -1, 0 e 1; Ideação, contemplando as etapas 2 e 3; e Implementação, englobando as etapas 4, 5 e 6 . Detalhamos a descrição de cada etapa abaixo. Ressalta-se que, no âmbito desta metodologia, efetuou-se a pesquisa até a Etapa 4, seguida de validação e testes.

Etapa (-1) OPORTUNIDADES: Verificação das oportunidades, conforme o produto ou projeto a ser avaliado, considerando um panorama local, nacional e internacional. Nesta etapa são evidenciadas as necessidades de crescimento do setor e outras necessidades conforme o produto.

Etapa (0) PROSPECÇÃO: Identificação e definição da demanda/problemática central que norteará o projeto. 
Etapa (1) LEVANTAMENTO DE DADOS: Etapa de definições do projeto com base em um levantamento de dados em conformidade com as necessidades e expectativas do usuário.

Etapa (2) ORGANIZAÇÃO E ANÁLISE DOS DADOS: Após o levantamento das informações, estas precisam ser organizadas e analisadas. Podem ser utilizadas técnicas analíticas que permitirão definir estratégias de projeto.

Etapa (3) CRIAÇÃO: Tendo as estratégias de projeto, são definidos, nesta etapa, os conceitos globais do projeto, sendo geradas alternativas preliminares. Essas alternativas são submetidas à uma nova análise, permitindo a escolha daquelas que respondem de melhor forma às especificações de projeto e atendimento dos objetivos.

Etapa (4) EXECUÇÃO: Nesta etapa, considera-se o ciclo de vida do produto em relação às propostas. A partir dessas, são desenvolvidos protótipos, para posteriormente elaborar 0 protótipo funcional da alternativa escolhida.

Etapa (5) VIABILIZAÇÃO: Sendo definida a proposta que melhor atende às especificações, nesta etapa o produto é testado em situação real (usabilidade), de forma a validá-lo.

Etapa (6) VERIFICAÇÃO: Esta etapa é considerada de vital importância, no sentido de que poderá gerar novas oportunidades, permitindo assim uma retroalimentação do percurso do Design. Em suma, um novo ponto de partida, rompendo com o pensando de linearidade (pensamento sistêmico).

\subsection{Oportunidades}

A partir do contexto já mencionado, dentro do laboratório, verificou-se a oportunidade de propor melhorias nas rotinas e processos (fluxos) da equipe de DG de um projeto voltado para o desenvolvimento de materiais didáticos digitais para EaD. A referida equipe é responsável por criar todas as animações, ilustrações e padrões visuais do material, além de fazer o processo de diagramação dos conteúdos educacionais criados (em formato de hipermídia) utilizando uma ferramenta específica desenvolvida pelo núcleo. Para gerir essas demandas, a equipe precisa estar em sintonia com as outras, para que os padrões gráfico-visuais planejados sejam implementados em todas as etapas do trabalho, devido ao modelo de gestão colaborativa do projeto - com fluxos complexos e envolvendo diversas equipes em diferentes momentos.

A oportunidade foi verificada quando, no dia-a-dia, percebeu-se que, para que o trabalho em equipe seja mais eficiente, algumas práticas precisam estar documentadas e serem facilmente acessadas. Nesse ponto, a importância da sistematização do conhecimento e dos processos mostra-se importante, já que equipes interdisciplinares estão envolvidas em diferentes etapas desta produção, conforme pontua Memória (2005).

\subsection{Prospecção}

Para que o desenvolvimento de materiais didáticos digitais seja eficaz, é necessário planejar e acompanhar um fluxo de trabalho específico visando a organização dos processos, principalmente em ambientes compostos por equipes interdisciplinares. Seguindo a perspectiva do design thinking, considera-se que a equipe já realiza autoavaliações de processos e vivências ao longo do projeto. Porém, ainda carece de sistematização.

Visualizando este cenário a partir da ótica do design thinking, instituições, empresas e organizações adeptas à esta metodologia, destacam-se por possuírem disposição em assumir a tarefa de continuamente repensar seus processos (MARTIN, 2010: 8).

Como a perspectiva do design thinking é criar valor desde as etapas iniciais de projeto até a inserção das ideias no mercado, a abordagem sugere uma

evolução de "fazer design" para "pensar design". Outros conceitos utilizados pelo design thinking são a abordagem centrada no ser humano, a interdisciplinaridade, a colaboração, o storytelling e a experimentação (CASAS; MERINO, 2011: 6). 
Partindo desse pressuposto, a proposta consistiu em mapear estratégias possíveis de implementação, para que a Equipe de DG possa, além de fazer design, pensar design e, como já falado anteriormente, planejar seus processos de forma mais organizada e sistematizada, possibilitando assim maior clareza das demandas.

Uma maior consciência sobre as formas de tratamento de problemas pelos designers gera percepções para novas abordagens (MOZOTA, 2011: 269).

Assim, além de perceber a importância da prática de repensar processos, a documentação também é efetivamente necessária, haja vista que esses materiais

[...] precisam manter uma coerência interna com os princípios pedagógicos adotados e com as mídias definidas para os cursos, privilegiando a interação com os alunos. O impacto dos materiais didáticos sobre as aprendizagens e a motivação dos estudantes estão diretamente vinculados a uma "produção extremamente cuidadosa, envolvendo um delicado trabalho com os conteúdos, com a didática, com as linguagens das mídias, com a organização visual e com os processos interativos" (GATTI, 2002 apud CERNY, 2009: 163).

Esta proposta pode ajudar, ainda, na interlocução com as outras equipes do projeto, pois quando se tem maior clareza das possibilidades e responsabilidades de cada equipe, num contexto interdisciplinar, seus membros conseguem pensar a nível macro, focando não só nos procedimentos internos de sua equipe, mas também nas maneiras de facilitar o trabalho do outro - minimizando a segmentação do trabalho. Além de poder incluir os membros de outras equipes em processos criativos inerentes à equipe de DG, maneira esta de também fazer com que todos sintam-se parte do contexto de desenvolvimento.

O envolvimento dos funcionários no processo criativo é fundamental para a apropriação, a coerência do projeto e a continuidade cultural (DORMER, 1990, apud MOZOTA, 2011: 198).

\subsection{Levantamento de dados}

Partindo da compreensão da oportunidade gerada, inicia-se a etapa de levantamento de dados. Nessa etapa, foram levantados os requisitos do material (guia), por meio de entrevistas semi-estruturadas e observação; além disso, buscou-se boas práticas já documentadas (por meio de pesquisa bibliográfica) e práticas recorrentes no cotidiano da equipe, que poderiam ser documentadas para facilitar o acesso e a consulta. A organização desta etapa é feita a partir de 3 blocos de informação de acordo com o GODP, conforme ilustrado abaixo.

Figura 4: Levantamento de dados
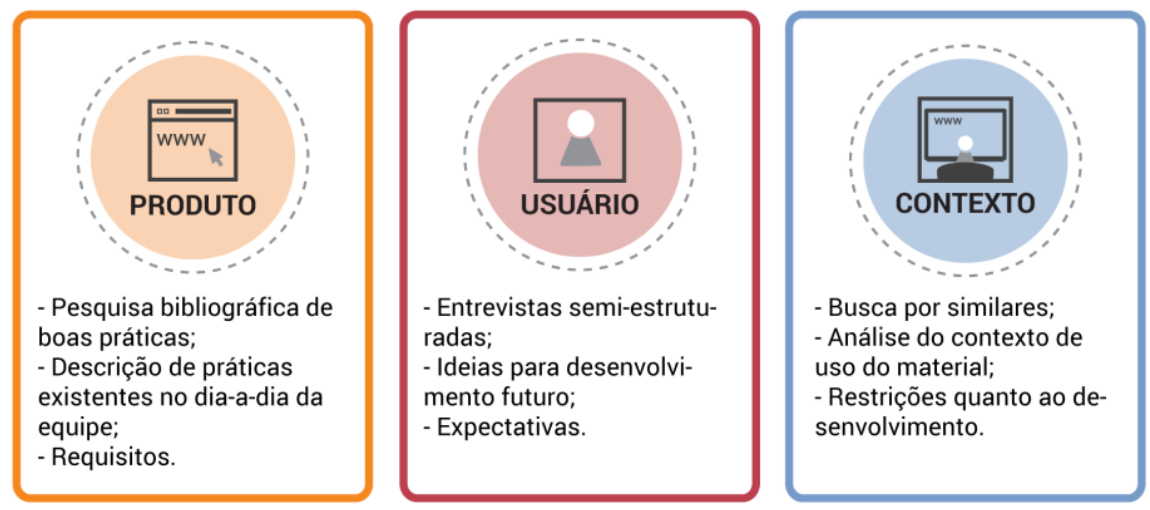

Fonte: Elaborada pelos autores (2016).

Em relação ao bloco "produto", no que se refere ao desenvolvimento do material em si, buscou-se boas práticas já documentadas (por meio de pesquisa bibliográfica) e práticas recorrentes no dia-a-dia da equipe, que poderiam ser documentadas para facilitar o acesso e a consulta. Em relação ao bloco "usuário", e com o objetivo de entender melhor as necessidades acerca do material proposto, foram feitas entrevistas semi-estruturadas com integrantes das equipes do projeto. Por fim, em relação ao bloco "contexto", algumas orientações e/ou restrições institucionais foram levantadas, tanto como resultado das entrevistas quanto como 
observações do dia-a-dia da equipe.

\subsection{Organização e análise de dados}

Neste momento de projeto, são apresentados os dados coletados e organizados, também de acordo com os blocos de informação: produto, usuário e contexto. Assim, em relação ao produto, foram sistematizadas boas práticas; em relação ao bloco usuário, foram sistematizados recortes das entrevistas feitas; e em relação ao bloco contexto, foi verificado que os processos relativos ao fluxo de trabalho são pouco mapeados e documentados, gerando (por vezes) falhas de comunicação, materiais com diferentes padronizações e retrabalho.

Como resultado desta etapa, foram gerados os requisitos de produto, a partir de seus usuários e seu contexto de uso.

\subsubsection{Requisitos}

Os requisitos de projeto foram gerados tanto por meio das entrevistas e observação do cenário quanto por meio de pesquisa bibliográfica, seguindo princípios básicos do design - com foco na melhoria dos processos. A relação dos requisitos relativos ao produto é apresentada a seguir.

- Documentar práticas da Equipe de Design Gráfico presentes no desenvolvimento de materiais didáticos digitais;

- Consolidar conhecimentos que estão sendo trabalhados na prática;

- Oferecer material de apoio para o dia-a-dia da equipe;

- Oferecer material de apoio aos coordenadores de projeto;

- Analisar sua eficácia e eficiência;

- Possibilitar atualizações, para que não se torne obsoleto, visto que os processos poderão ser repensados;

- Colaborar com a documentação de fluxos e processos no contexto pesquisado;

- Colaborar com a imersão dos membros das equipes no projeto, apontando a importância dos fluxos e de pensar e repensar práticas;

- Deverá seguir padrão visual do próprio laboratório;

- Deverá ser implementado utilizando sistema próprio da universidade;

- Categorização: sumário (com todas as equipes presentes na estrutura organizacional do projeto); menu com os seguintes itens: a) fundamentos de EaD; b) princípios básicos de design; c) projetando para Web; d) processos internos.

Enquanto requisitos relativos ao usuários, foram levantados:

- Equipes de criação e desenvolvimento de materiais didáticos digitais;

- Gestores e/ou Supervisores de projeto;

- Coordenadores de projeto.

Por fim, enquanto requisitos relativos ao contexto:

- O material não deve ser utilizado para fins lucrativos;

- O material deve prezar por flexibilidade;

- Necessitará passar por aprovação da coordenação do projeto;

- A utilização da primeira versão se dará dentro do laboratório;

- Sua não-utilização não gera nenhum tipo de problema para os projetos do laboratório.

\subsection{Criação}

Nesta etapa foram definidos os conceitos gerais do guia (Figura 5), utilizando-se de uma nuvem de palavras; e por conseguinte, iniciou-se a geração de alternativas (Figura 6), para posterior escolha da alternativa mais coerente com os requisitos levantados. 


\section{CIDI 2017

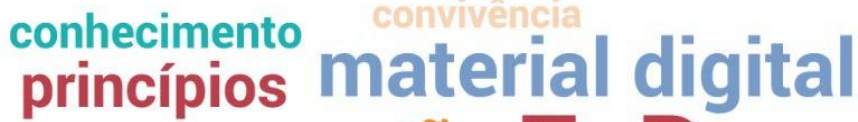 práticas gestão EaD fluxOS documentação experiências flexibilidade organização}

Fonte: Elaborada pelos autores (2016)

Figura 6: Geração de alternativas

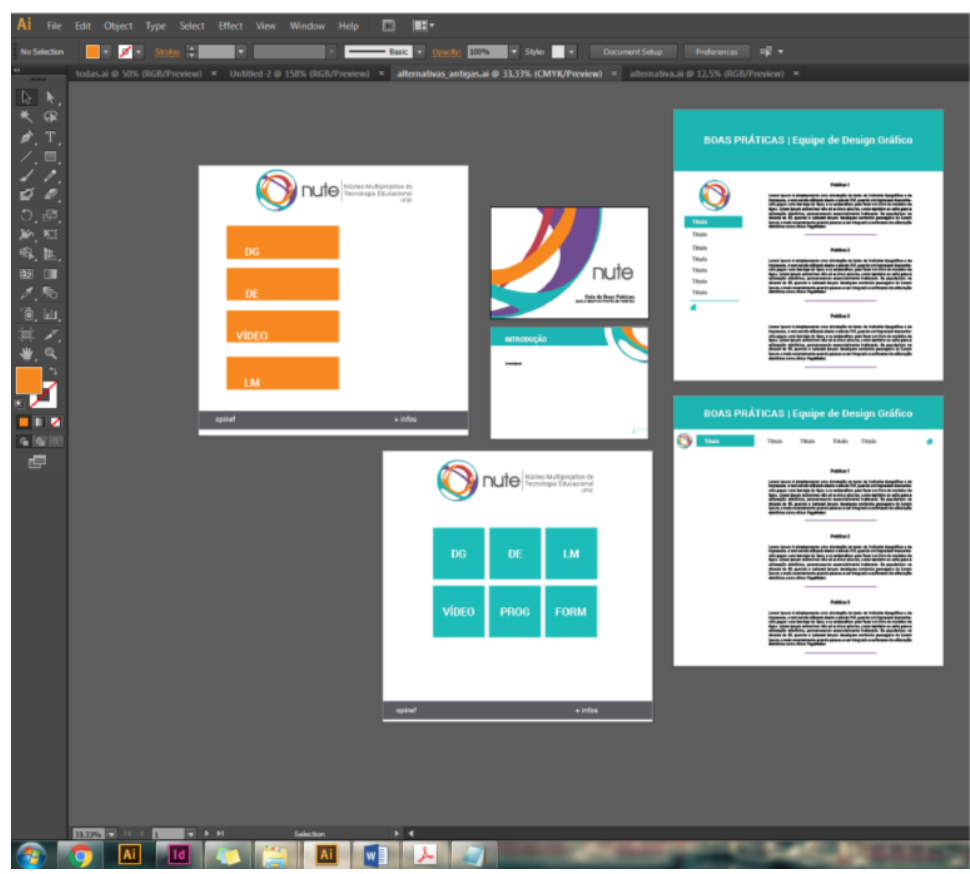

Fonte: Elaborada pelos autores (2016)

Para a seleção da proposta considerada mais adequada, levou-se em consideração outros materiais já desenvolvidos pelo laboratório, e a capacidade deste guia ser tão simples e claro, quanto outros materiais já desenvolvidos. Optou-se por uma proposta familiar à identidade do laboratório, visando ser um material de fácil apropriação e atualização.

\subsection{Execução}

O protótipo do guia foi desenvolvido por meio de sistema próprio (UFSC), utilizado cotidianamente para o desenvolvimento de hipermídias educacionais em determinados projetos. Foi utilizada a alternativa escolhida para a criação dos templates - telas de diagramação do material. Para a etapa de implementação, foi necessária a ajuda de um desenvolvedor front-end e back-end e, após essa etapa, deu-se início à diagramação e 
refinamento do material. O protótipo pode ser acessado por meio de link específico (http://sgmd.nute.ufsc.br/content/boas-praticas-nute/guia/capa.html), hospedado dentro do referido laboratório.

\section{Validação do protótipo}

Com o protótipo finalizado, iniciou-se o período de testes. A validação foi realizada com integrantes de todas as equipes do projeto (Design Gráfico, Design Educacional, Revisão Textual, Programação, Vídeo e Coordenação Geral). Optou-se por não solicitar validação somente à equipe de DG (foco desta pesquisa) para que houvesse um feedback global - haja vista que os resultados possibilitam pesquisas futuras.

A estrutura definida para os testes foi padronizada da seguinte maneira: após uma explanação inicial sobre a pesquisa (por e-mail e/ou pessoalmente) e assinatura do Termo de Consentimento Livre e Esclarecido (TCLE), foi disponibilizado link de acesso ao material e solicitado que os participantes navegassem pelo guia. Feito isso, foi solicitado que os participantes respondessem a um questionário online (previamente criado). As respostas documentadas por meio do formulário foram utilizadas como registro da atividade e documentação da pesquisa, além de servirem como panorama de desenvolvimento futuro - no caso de sugestões.

Como resultado, diversas sugestões foram apontadas (e algumas puderam ser implementadas). Verifica-se, através dos resultados apresentados a seguir, as percepções acerca do material e sua importância.

\subsection{Resultados do questionário aplicado}

- "O mesmo explica a importância de certos elementos na construção de um material gráfico de Ead";

- "Organização de muitas equipes e pessoas; Separação de materiais; Feedback rápido; facilidade de acesso ao material; concentração de todo material num mesmo lugar";

- "Serviria como um guia de consulta rápida com informações concentradas num só lugar a respeito dos métodos e processos utilizados";

- "Porque indica uma série de fatores relevantes na produção de design gráfico";

- "Pelos motivos listados no próprio "Sobre"”;

- "Esse material, por mostrar um processo no que diz respeito à produção de material para o ensino a distância, pode ser útil para empresas que produzem hipermídias e para o próprio Ead da UFSC, que precisa se atualizar";

- "Pode contribuir com a construção de novos guias de equipe, ou ainda, por meio de formações, com as equipes a respeito dos temas tratados";

- "Por orientar vários aspectos importantes para o desenvolvimento de materiais";

- "Ambientação de novos integrantes na equipe";

- "Acredito que será útil principalmente para novos integrantes das equipes, que poderão entender o contexto de trabalho do laboratório de forma prática, ou seja, através de um Guia Digital";

- "Possibilitar reunir informações e bases teóricas que ancoram o trabalho das distintas equipes envolvidas no desenvolvimento de materiais para EaD";

- "Porque é uma síntese de vários elementos presentes nos projetos em que trabalhamos. Embora traga reflexões a partir da literatura, essas partem da prática de criação e desenvolvimento de materiais e é aí que me parece que reside a potência desse guia. Não me parece ser um simples apanhado de conceitos teóricos tratados de forma abstrata, mas uma conceituação de práticas ou elementos presentes nas 
práticas";

- "Entendo que o material direciona ao entendimento dos principais fundamentos na criação de um site Ead. Além disso, apresenta, na prática, esses conceitos na realidade do laboratório";

- "Por ser um guia de fácil acesso, facilitando a comunicação sobre tópicos importantes para atuação de toda a equipe e para o projeto, se tornando também uma espécie de formação interna para quem chega na equipe".

\section{Resultados}

Como estratégia de design, constatou-se que a utilização de um fluxo de processos pode ajudar os integrantes da equipe a planejarem melhor suas demandas. A ideia de utilizar uma hipermídia como fonte de informação, dentro de um sistema já consolidado pela equipe, reforça o feedback positivo dado pela equipe, pois facilita o trabalho.

Porém, analisando o contexto atual, pode-se concluir que esta importante prática de sistematização de informações ainda é pouco difundida na equipe. Para fomentar cada vez mais esse aspecto, sugere-se, por fim, que seja utilizado um ciclo de processos (Figura 7) podendo ser relacionado à gestão de design, criado a partir da execução desta pesquisa.

Figura 7: Ciclo de processos

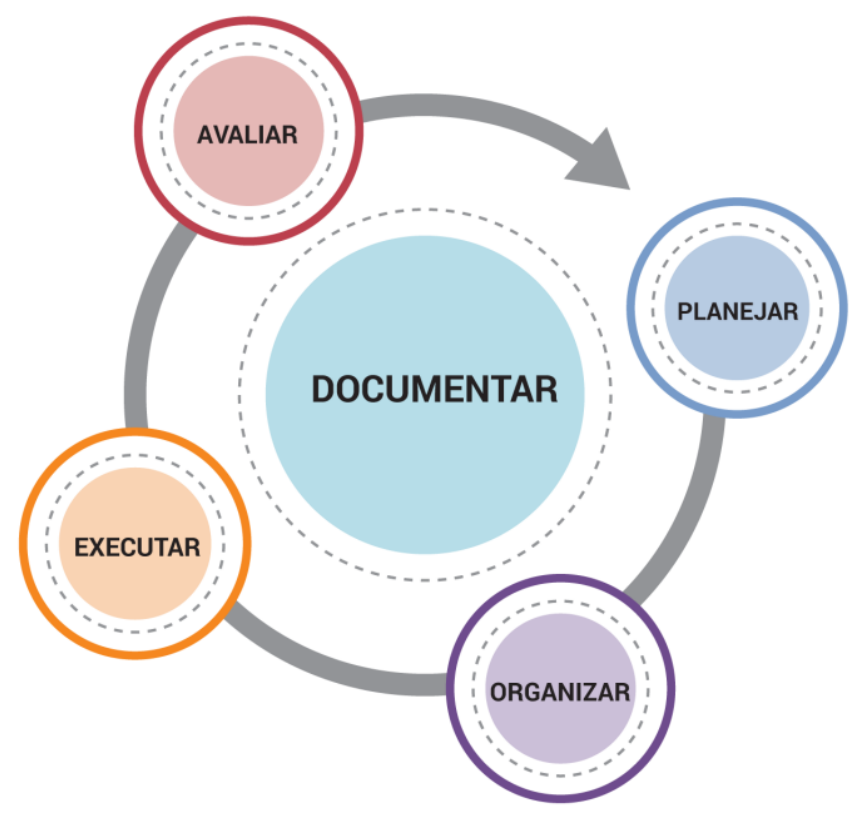

Fonte: Elaborada pelos autores (2016)

O ciclo proposto acima é composto por quatro (04) etapas, sendo que a documentação (ou sistematização) precisa permear todas elas.

\section{Considerações finais}

Com a execução dos testes do protótipo, foi verificado que o material pode efetivamente colaborar para que os processos de desenvolvimento de materiais sejam melhor projetados e documentados. O guia funcionou como um repositório de informações importantes, princípios a serem levados em consideração, e processos que ficam documentados - fomentando a sistematização de conhecimento e demonstrando a importância do design da informação no contexto de projetos educacionais. 


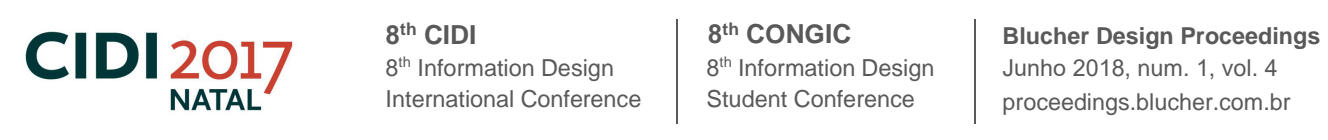

A nível global, considera-se que a criação de um guia para cada equipe, em contextos interdisciplinares, pode trazer ainda mais melhorias para os processos, visto que estas equipes estão em constante interlocução e precisam ficar cientes de diversas informações no dia-a-dia.

Como panorama futuro, sugere-se o estudo aprofundado das outras equipes pertencentes à estrutura organizacional apresentada, podendo gerar dados muito ricos acerca do impacto da hipermídia em contextos educacionais; da relação entre design e organização de processos (gestão de design, design de interfaces, design de informação), e ainda possibilitando a criação de um material mais completo, demonstrando outros vieses do cenário de desenvolvimento de materiais didáticos.

\section{Referências}

ALAVA, Séraphin (Org.). Ciberespaço e formações abertas: rumo a novas práticas educacionais? Porto Alegre: Artmed, 2002. 224 p.

BELLONI, Maria Luiza. Educação a distância. Campinas: Autores Associados, 1999.

CASAS, Diego Daniel; MERINO, Eugenio Andrés Díaz. Gestão de Design \& Design Thinking: uma relação possível. In: e-Revista LOGO. Florianópolis, 2011, v. 11, p. 1-7.

CERNY, Roseli Zen. Gestão pedagógica na educação a distância: análise de uma experiência na perspectiva da gestora. 2009. 257 f. Tese (Doutorado) - Pontifícia Universidade Católica de São Paulo, Curso de Pós-graduação em Educação.

MARTIN, Roger. Design de negócios: por que o design thinking se tornará a próxima vantagem competitiva dos negócios e como se beneficiar disso. Rio de Janeiro: Elsevier, 2010.

MARTINS, Rosane Fonseca Freitas; MERINO, Eugenio Andrés Diaz. Gestão de design como estratégia organizacional. Londrina: Eduel, 2008. 250 p.

MEMÓRIA, Felipe. Design para a internet: Projetando a Experiência Perfeita. Rio de Janeiro: Elsevier, 2005. $171 \mathrm{p}$.

MERINO, Giselle Schmidt Alves Díaz. Metodologia para a prática projetual do Design com base no Projeto Centrado no Usuário e com ênfase no Design Universal. 2014. 212 f. Tese (Doutorado) - Universidade Federal de Santa Catarina, Curso de Programa de Pós-Graduação em Engenharia de Produção.

GODP - Guia de Orientação para Desenvolvimento de Projetos: Uma metodologia de Design Centrado no Usuário. Florianópolis: Ngd/Ufsc, 2016. Disponível em: <www.ngd.ufsc.br>. Acesso em: 20 jun. 2017.

MOZOTA, Brigitte Borja. Gestão do Design: Usando o design para construir valor de marca e inovação corporativa. Porto Alegre: Bookman, 2011.

PORTUGAL, Cristina. Design, educação e tecnologia. 1 ed. Rio de Janeiro: Rio Books, 2013.

RENNEBERG, Mônica. Contribuições do design para a evolução do hiper-livro do AVEA-

LIBRAS: o processo de desenvolvimento de interfaces para objetos de aprendizagem. 2010.

243 f. Dissertação (Mestrado em Design) - Universidade Federal de Santa Catarina,

Florianópolis, 2010.

ROYO, Javier. Design Digital. São Paulo: Edições Rosari, 2008.

SEIDEL, Victor. Moving from Design to Strategy: The 4 roles of Design-Led strategy Consulting. Design Manegement Journal. VOL. 11, no. 2, 2000, Spring.

UNIVERSIDADE FEDERAL DE SANTA CATARINA. Secretaria de Educação a Distância.

Missão e Visão. 2017. Disponível em: <http://www.sead.ufsc.br/missao-e-visao/>. Acesso em: 10 jul. 2017. 


\section{Sobre os autores}

Jaqueline de Ávila, Mestranda do Programa de Pós-Graduação em Design, UFSC, Brasil, jaqueline.avl@gmail.com.

Giselle Schmidt Alves Díaz Merino, Doutora em Engenharia de Produção, UFSC, Brasil, gisellemerino@gmail.com.

Eugenio Andrés Díaz Merino, PhD em Engenharia de Produção, UFSC, Brasil, eugenio.merino@ufsc.br. 